Review Article

\title{
Theory of Language and Meaning in Phenomenological Structuralism
}

\author{
Paul C Mocombe* \\ Department of Sociology, West Virginia State University, USA
}

*Corresponding author: Paul C Mocombe, Department of Sociology, West Virginia State University, The Mocombeian Foundation, USA.

Received Date: April 26, 2019

Published Date: May 10, 2019

\begin{abstract}
This work explores the nature of language and meaning according to Paul C. Mocombe's structurationist theory of phenomenological structuralism. The author posits that language is a tool used in human society to both capture the nature of reality as such, and how we ought to recursively organize and reproduce our being-in-the-world within the aforementioned systemicity or structure despite the human potential to defer meaning in ego-centered communicative discourse.
\end{abstract}

Keywords: Structurationism; Praxis; Panpsychism; Social class language game; Phenomenological structuralism; ORCH-OR theory

\section{Introduction}

Paul C Mocombe's [1] structurationist theory of phenomenological structuralism, in keeping with the logic of structurationist sociology, assumes practical activity and consciousness, i.e., practical consciousness, to be the basis for understanding human behavior and consciousness in the world. Consciousness here refers to subjective awareness of phenomenal experiences (ideology, language, self, feelings, choice, control of voluntary behavior, thoughts, etc.) of internal and external worlds. The academic literature "describes three possibilities regarding the origin and place of consciousness in the universe: (A) as an emergent property of complex brain neuronal computation, (B) as spiritual quality of the universe, distinct from purely physical actions, and (C) as composed of discrete 'proto-conscious' events acting in accordance with physical laws not yet fully understood" Hameroff \& Penrose [2]. The latter position, (C), represents the ORCH-OR ("orchestrated objective reduction") theory of [2], which includes aspects of (A) and (B), and posits that "consciousness consists of discrete moments, each an 'orchestrated' quantum-computational process terminated by... an action objective reduction or OR rooted in quantum aspects of the fine structure of space-time geometry, this being coupled to brain neuronal processes via microtubules". In this view, the understanding is that a protoconscious experience existed in the universe, panpsychism, and as a result of emergent structures of the brain it (proto-conscious experience, psychion) became embodied and evolved as a result of quantum neuronal computations of "brains".

Paul C Mocombe's [1,3] structurationist sociology, phenomenological structuralism, which attempts to resolve the structure/agency problematic of the social sciences, builds on the ORCH-OR theory and panpsychism of [2], while holding on to the multiverse hypothesis of quantum mechanics and Haitian ontology/epistemology, which the authors reject because it is not "a more down-to-earth viewpoint" [2]. For [1,3] quantum superposition, entanglement, and evidence in Haitian Vodou of spirit possession, which represent ancestors from a parallel world, Vilokan, of the earth's of which we ought to pattern our behaviors and structures, are grounding proofs for the acceptance of the multiple worlds hypothesis of quantum mechanics. Within the latter hypothesis, the understanding is that "each possibility in a superposition evolves to form its own universe, resulting in an infinite multitude of coexisting 'parallel' worlds. The stream of consciousness of the observer is supposed somehow to 'split', so that there is one in each of the worlds-at least in those worlds for which the observer remains alive and conscious. Each instance of the observer's consciousness experiences a separate independent world and is not directly aware of any of the other worlds" [2]. It is within this multiple world's hypothesis that Mocombe constitutes the notion of consciousness in the universe according to his theory 
of phenomenological structuralism. For Mocombe, consciousness is a fifth force of nature, a quantum material substance/energy, psychion, the phenomenal property of which is recycled/entangled/ superimposed throughout the multiverse and becomes embodied via the microtubules of brains. It is manifested in simultaneous, entangled, superimposed, and interconnecting material resource frameworks as embodied praxis or practical consciousness, which in-turn becomes the phenomenal properties of material (subatomic particle energy, psychion) consciousness that is recycled/ entangled/superimposed throughout the multiverses.

\section{Theory and Method}

Structurationist sociology synthesizes structure and agency via the concept of praxis or practical consciousness; accounting for agency or practical consciousness via the actions associated with structural reproduction and differentiation within a particular material resource framework [4,5]. Building on structurationist sociology, Mocombe argues that the "moments, or movements, which escape from the compound of socially constructed identifications" are the product of an individual actors' (mental) stance/analytics (Martin Heidegger's term) vis-à-vis three types of structures/systems of signification amidst the practical consciousness associated with societal structural reproduction and differentiation (the social system): 1) the (chemical, biological, and physiological) drives (forms of sensibility and understanding) of the body and brain (the biological system), 2) impulses or phenomenal properties of residual past consciousnesses or recycled/entangled/ superimposed subatomic/chemical particles encapsulated in and as the neuronal energies of the brain via microtubules (the physical system), 3) and actions or practical consciousnesses resulting from the deferment of meaning in ego-centered linguistic and symbolic communicative discourse (the linguistic system) $(2018,2019)$.

Generally speaking, consciousnesses, actions (practical consciousness), learning, and development within Mocombe's phenomenological structural ontology are the product of the embodiment of the phenomenal properties of recycled/entangled/ superimposed subatomic neuronal energies/chemicals, psychion, of the multiverse objectified in the space-time of multiverses via the aggregated body and the microtubules of the brain[6-9]. Once objectified and embodied the phenomenal properties of the neuronal energies/chemicals encounter the space-time of physical worlds via a transcendental subject of consciousnesses (the aggregation of a universal-self superimposed and entangled across the multiple worlds of the multiverse) and the drives and sensibilities of the aggregated body and brain in reified structures of signification, language, ideology, ideological apparatuses, and communicative discourse defined and determined by other beings that control the resources (economics), and modes of distributing them, of the material world required for physical survival in spacetime. The Heideggerian (mental) stances/analytics, "ready-tohand," "unready-to-hand," and "present-at-hand," which emerge as a result of conflict between the embodied transcendental ego vis-à-vis its different systems, 1) the sensibilities and (chemical, biological, and physiological) drives of the body and brain, 2) drives/impulses of embodied residual memories or phenomenal properties of past recycled/entangled/superimposed subatomic/ chemical particles, 3) the actions produced via the body in relation to the indeterminacy/deferment of meaning of linguistic and symbolic signifiers as they appear to individuated consciousnesses in ego-centered communicative discourse, 4) and the dialectical and differentiating effects, i.e., structural reproduction and differentiation, of the structures of signification, social class language game, of those who control the economic materials (and their distribution, i.e., mode of production) of a world are the origins of practical consciousnesses [10-15]. All four types of actions, the drives and sensibilities of the body and brain, drives or phenomenal properties of embodied recycled/entangled/superimposed past consciousnesses, structural reproduction/differentiation stemming from the mode of production, and deferential actions arising from the deferment of meaning in ego-centered communicative discourse via the present-at-hand stance/analytic, exist in the material world with the social class language game, i.e., the physical, mental, emotional, ideological, etc. 5) powers of those who control the material resource framework as the causative agent for individual behaviors[16,19]. In other words, our (mental) stances in consciousness vis-à-vis the conflict between the (chemical, biological, and physiological) drives and sensibilities of the body and brain, (societal) structural reproduction and differentiation, drives of embodied past consciousnesses of recycled/entangled/ superimposed subatomic/chemical particles, and deferential actions arising as a result of the deferment of meaning in egocentered communicative discourse determines the practical consciousness we want to recursively reorganize and reproduce in the material world. The power and power positions of those who control (via the mode of production, language, ideology, ideological apparatuses, and communicative discourse) the resources (and their distribution, i.e., mode of production) of a material resource framework, and the threat it poses to the ontological security of an actor, in the end determines what actions and identities are allowed to organize and reproduce in the material world without the individual actor/agent facing marginalization or death.

It is Being's (mental/cognitivie) stance/analytic, "ready-tohand," "unready-to-hand," and "present-at-hand," in consciousness vis-à-vis the conflict, or lack thereof, between the (chemical, biological, and physiological) drives and sensibilities of the aggregated body and brain, drives/impulses (phenomenal properties) of residual past consciousnesses of recycled/entangled/ superimposed subatomic particles, alternative practices which arise as a result of phenomenological meditation and deferment of meaning, along with the differentiating logic or class divisions of the social relations of production, which produces the variability of actions and practices in cultures, social structures, or social systems. All four types of actions are always present and manifested in a social structure to some degree contingent upon the will and desires of the economic social class that controls the material resource framework through its body (practical consciousness), 
language/symbols, ideology, ideological apparatuses, and social relations of production. They choose, amidst the class division of the social relations of production, what other meaning constitutions and practices are allowed to manifest themselves in the material world without facing alienation, marginalization, domination, or death. Hence, we never experience the things-in-themselves of the world culturally and historically in consciousness. We experience them structurally or relationally, the structure of the conjuncture of the mode of production, its language, ideology, ideological apparatuses, etc., and our (mental/cognitive) stances/analytics, ready-to-hand, unready-to-hand, present-at-hand, vis-à-vis these things as they appear to and in consciousness determine our practical consciousness or behaviors.

We initially know, experience, and utilize the things of and in consciousness in the preontological ready-to-hand mode, which is structural and relational [20-24]. That is, our bodies encounter, know, experience, and utilize the things of the world in consciousness, intersubjectively, via their representation as objects of knowledge, truth, usage, and experience enframed and defined in the relational logic and practices or language game (Wittgenstein's term) of the institutions or ideological apparatuses of the other beings-of-the-material resource framework whose historicity comes before our own and gets reified in and as the actions of their bodies, language, ideology, ideological apparatuses, mode of production, and communicative discourse. This is the predefined phenomenal structural, i.e., ontological, world we and our bodies are thrown-in in coming to be-in-the-world. How an embodiedhermeneutically-structured Being as such solipsistically view, experience, understand, act, and utilize the predefined objects of knowledge, truth, and experienced defined by others and their conditions of possibilities in consciousness in order to formulate their practical consciousness is albeit indeterminate. Martin Heidegger in Being in Time is accurate, however, in suggesting that three stances or modes of encounter (Analytic of Dasein), "presence-at-hand," "readiness-to-hand," and "un-readiness-tohand," characterizes our views of the things of consciousness represented intersubjectively via bodies, language, ideology, and communicative discourse, and subsequently determine our practical consciousness or social agency. In "ready-to-hand," which is the preontological mode of human existence thrown in the world, we accept and use the things in consciousness with no conscious experience of them, i.e., without thinking about them or giving them any meaning or signification outside of their intended usage. Heidegger's example is that of using a hammer in hammering. We use a hammer without thinking about it or giving it any other condition of possibility outside of its intended usage as defined by those whose historicity presupposes our own. In "present-at-hand," which, according to Heidegger, is the stance of science, we objectify the things of consciousness and attempt to determine and reify their meanings, usage, and conditions of possibilities as the nature of reality as such. Hence the hammer is intended for hammering by those who created it as a thing solely meant as such. The "unreadyto-hand" outlook is assumed when something goes wrong in our usage of a thing of consciousness as defined and determined by those who adopt a "present-at-hand" view. As in the case of the hammer, the unready-to-hand view is assumed when the hammer breaks and we must objectify it, by then assuming a present-athand position, and think about it in order to either reconstitute it as a hammer, or give it another condition of possibility. Any other condition of possibility that we give the hammer outside of its initial condition of possibility which presupposed our historicity becomes relational, defined in relation to any of its other conditions of possibilities it may have been given by others we exist in the world with who either ready-to-hand, unready-to-hand, or present-athand attempts to maintain the social class language game of power. In the ready-to-hand stance the latter unconsciously practices and attempts to reproduce the social class language game of power by discriminating against and marginalizing any other conditions of possibilities of their social class language as determined by those in ideological power positions. They may move to the unready-tohand stance in response to those who they encounter that attempts, present-at-hand, to alter the nature of the dominant social class language game they recursively reorganize and reproduce as outlined by those in power positions who are present-at-hand of the dominant social class language game. In either case, not all beings achieve the present-at-hand stance [25-28]. The latter is the stance of science and ideologies, which are tautologies when they profess that their stances represent the nature of reality as such, and those in power positions, who choose, among a plethora of alternative present-at-hand social class language games, what alternative practical consciousnesses outside of their social class language game that are allowed to manifest in the material world.

\section{Discussion and Conclusion}

Hence, as outlined above, phenomenological structuralism posits consciousness to be the by-product or evolution of subatomic particles unfolding with increasing levels of abstraction within a material resource framework enframed by the mode of production, language, ideology, ideological apparatuses, and communicative discourse of bodies (who control the material resource framework) recursively reorganizing and reproducing the ideals of the latter factors as their practical consciousness. Thus, in phenomenological structuralism the understanding is that the structure of reality determines language (via its generative grammar) and how we ought to live in the world. However, the language, and its usage, i.e., social class language game, of those who control the material resource frameworks of the world conceals that relationship via their mode of production, ideologies, ideological apparatuses, and communicative discourse, which is evolutionary. In other words, like the Wittgensteinian position of the Tractatus, Mocombe's theory of phenomenological structuralism assumes that there is a uniform (grammatical) structure to language determined by the logical-empirical structure of (quantum and physical) reality. The grammatical structure of linguistic utterances attempts to capture the subjects and objects of that reality and how we ought to live in it and with them. In being-in-the-world with others, this logicalgrammatical structure, however, is concealed by the developmental 
knowledge, and its usage (practical activity), of those who control the material resource framework of the world via the stage of development of their language, ideology, ideological apparatuses, social relations of production, and communicative discourse[29]. Be that as it may, the latter comes to constitute an evolutionary social class language whose linguistic systemicity and usage comes to determine our conception of reality, and the classes, categories, and forms of life we belong to and interact in and with, which depending on its stage of development and relation to the True nature of reality as such, is either accepted or constantly deferred by those in its speech community who are marginalized or not represented in its evolutionarily developed linguistic systemicity. The latter process under the guise "language game," language as a tool, is what Wittgenstein captures in his second treatise on language as developed in the Philosophical Investigations. That is, the classes and categories created by the dominant social class language game of a material resource framework constitute reified classes, categories, and forms of life, "language games," whose meanings and praxes as defined by the dominant social class language game are either accepted or deferred by those classified in them. So in Mocombe's theory of phenomenological structuralism, Wittgenstein's two theories of language and meaning must be read as one philosophy as opposed to two, one supported by analytical philosophy and the other by postmodernism/post-structuralism. We have a plethora of language games (classes, forms of life, and categories) in the world, which structures our language, because of the ability to defer meaning in ego-centered communicative discourse and the developmental stage of the human mind and body vis-à-vis the actual structure of reality [30,31]. The language of science, like its predecessor religion, attempts to capture the logical-empirical structure of (quantum and physical) reality, and how we ought to live within it, amidst the utterances and practical consciousnesses of the masses given their abilities to defer meaning in ego-centered communicative discourse and the classes, categories, and forms of life they are classed in/with by the dominant social class language game.

Hence in the end, consciousness (praxis) and subject constitution is a product of conflict, or lack thereof, and an individual's (mental/cognitive) stance, i.e., analytics, vis-à-vis three structures of signification and the ability to defer meaning in ego-centered communicative discourse stemming from the social class language game (i.e., language, symbols, ideology, ideological apparatuses, and communicative discourse) of those who control the mode of production of a material resource framework. It is the ready-to-hand drives of the body and brain, ready-to-hand and present-at-hand manifestation of past recycled/entangled/ superimposed residual consciousnesses/subatomic particles, the present-at-hand phenomenological meditation and deferment of meaning that occurs in embodied consciousness via language, ideology, and communicative discourse as reflected in diverse individual practices, within the ready-to-hand, unready-to-hand, and present-at-hand differentiating logic or class divisions of the social relations of production, which produces the variability of actions and practices in cultures, social structures, or social systems. All four types of actions, the (chemical, biological, and physiological) drives/impulses of the body and residual past consciousnesses of subatomic particles, structural reproduction/differentiation, and actions resulting from the deferment of meaning in ego-centered communicative discourse, are always present and manifested in a social structure (which is the reified ideology via ideological apparatuses, their social class language game, of those who control a material resource framework) to some degree contingent upon the will and desires of the economic social class that controls the material resource framework through the actions of their bodies (practical consciousness), language, symbols, ideology, ideological apparatuses, and social relations of production [32]. They choose, amidst the evolutionary class division of the social relations of production, "the structure of the conjuncture," (Marshall Sahlins's term) what other meaning constitutions and practices are allowed to manifest themselves without the Beings of that practice facing alienation, marginalization, domination, or death.

The individual being is initially constituted as superimposed, entangled, recycled, and embodied subatomic particles of multiple worlds of the multiverse, which have their own predetermined form of understanding and cognition, phenomenal properties, based on previous or simultaneous experiences as aggregated matter (this is akin to what the Greek philosopher Plato refers to when he posits knowledge as recollection of the Soul). Again, the individual's actions are not necessarily determined by the embodiment and drives of these recycled/entangled/superimposed subatomic particles. It is conflict and an individual's stance, ready-to-hand, unready-tohand, and present-at-hand, when the subatomic particles become aggregated matter or embodied, which determines whether are not they become aware, present-at-hand, of the subatomic particle drives and choose to recursively reorganize and reproduce the content of the drives as their practical consciousness.

This desire to reproduce the cognition and understanding of the (chemical, biological, and physiological) drives of the recycled/ entangled/superimposed subatomic particles, however, may be limited by the structuring structure of the aggregated body and brain of the individual subject. That is to say, the second origins and basis of an individual's actions are the structuring drives and desires, for food, clothing, shelter, social interaction, and sex, of the aggregated body and brain, which the subatomic particles constitute and embody. In other words, the aggregated body and brain is preprogrammed with its own (biological) forms of sensibility, understanding, and cognition, structuring structure, by which it experiences being-in-the-world as aggregated embodied subatomic particles [32-35]. These bodily forms of sensibility, understanding, and cognition, such as the drive and desire for food, clothing, shelter, social interaction, linguistic communication, and sex, are tied to the material embodiment and survival of the embodied individual actor, and may or may not supersede or conflict with the desire and drive of an individual to recursively (re) organize and reproduce the structuring structure of the superimposed, entangled, and recycled (phenomenal properties of) subatomic particles. If these two initial 
structuring structures are in conflict, the individual moves from the ready-to-hand to the unready-to-hand stance or analytics where they may begin to reflect upon and question their being-in-theworld prior to acting. Hence just as in the case of the structuring structure of the subatomic particles it is an individual being's analytics vis-à-vis the drives of its body and brain in relation to the impulses of the subatomic particles, which determines whether or not they become driven by the desire (actions/praxis) to solely fulfill the material needs of their body and brain at the expense of the drives/desires of the subatomic particles or the social class language game of the material resource framework they find their existence unfolding in.

The social class language game, and its differentiating effects, an individual find their existence unfolding in is the third structuring structure, which attempts to determine the actions of individual beings as they experience being-in-the-world as embodied subatomic particles. The aggregated individual finds themselves objectified and unfolding within a material resource framework controlled by the actions of other bodies, which presuppose their existence, via the actions of their bodies (practical consciousness), language, communicative discourse, ideology, and ideological apparatuses stemming from how they satisfy the desires of their bodies and subatomic particle drives (means and mode of production). What is aggregated as a social class language game by those in power positions via and within its mode of production, language, ideology, ideological apparatuses, and communicative discourse attempts to interpellate and subjectify other beings to its interpretive frame of satisfying their bodily needs, fulfilling the impulses of their subatomic particles, and organizing a material resource framework at the expense of all others, and becomes a third form of structuring individual action based on the mode of production and how it differentiates individual actors.

That is to say, an individual's interpellation, subjectification, and differentiation within the social class language game that presupposes their being-in-a-world attempts to determine their actions or practical consciousness via the reified language, ideology, etc., of the social class language game, the meaning of which can be deferred via the communicative discourse of the individual actors. Hence, the deferment of meaning in ego-centered communicative discourse of the language and ideology of a social class language game is the final means of determining an individual's action or practical consciousness outside of, and in relation to, its stance, i.e., analytics, vis-à-vis the drives of subatomic particles, drives and desires of the body and brain, and structural reproduction and differentiation.

Whereas the practical consciousness of the transcendental ego stemming from the impulses of embodied subatomic particles are indeterminant as with its neuronal processes involved with the constitution of meaning in ego-centered communicative discourse (Albeit physicists are in the process of exploring the nature, origins, and final states of subatomic particles, and neuroscientists are attempting to understand the role of neuronal activities in developing the transcendental ego and whether or not it continues to exist after death). The form of the understandings and sensibilities of the body and brain are determinant as with structural reproduction and differentiation of the mode of production, and therefore can be mapped out by neuroscientists, biologists, and sociologists to determine the nature, origins, and directions of societal constitution and an individual actor's practical consciousness unfolding.

The interaction of all four elements or processes in relation to the stance of the transcendental ego of the individual actor is the basis for human action, praxis/practical consciousness in a world. However, in the end, consequently, the majority of practical consciousness will be a product of an individual actor's embodiment and the structural reproduction and differentiation of a social class language game given 1) the determinant nature of embodiment, form of understanding and sensibility of the body and brain amidst, paradoxically, the indeterminacy of impulses of embodied subatomic particles and the neuronal processes involved in ego-centered communicative discourse; and 2) the consolidation of power of those who control the material resource framework wherein a society, the social class language game, is ensconced and the threat that power (consolidated and constituted via the actions of bodies, mode of production, language, ideology, ideological apparatuses, and communicative discourse) poses to the ontological security of an aggregated individual actor who chooses (or not) either ready-to-hand or present-at-hand to recursively reorganize and reproduce the ideals of the society as their practical consciousness [35-37]. It should be mentioned that in response to this latter process, those in power positions who internalize the ideals of the social structure and recursively (re) organize and reproduce them as their practical consciousness are in the unreadyto-hand stance when they encounter alternative forms of being-inthe-world within their social class language game. They dialectically attempt to reconcile the practical consciousness of their social class language game with the reified practical consciousness of those who have deferred their meanings for alternative forms of being-inthe-world within their social class language. They can either accept, marginalize, or seek to eradicate the deferred or decentered subject or their practices.

Hence within the theory and methodology of phenomenological structuralism, there is, contrary to David Hume's "bundle of perception" hypothesis, a human essence, which is tied to the embodiment and structuring structure of the phenomenal properties of superimposed, entangled, embodied, and recycled subatomic particles, the processes of which are unbeknownst to us as of the writing of this work, as they are recursively reorganized and reproduced via the superverse and its multiverses. Just the same, Universalism and Truth are also tied to the science and physics of the remaining processes of phenomenological structuralism. Subatomic/chemical particles with phenomenal properties constitute objects and subjects that are external and internal to the perceiving human actor who know them (the objects and subjects) as both external and internal phenomenon endowed with, and mediated by, linguistic and ideological meanings, stemming from 
the modes of production, of other human actors who presupposed their aggregated existence. The essence, universalism, and Truth of an object and subject lies in the phenomenal properties of their subatomic and chemical particles once demystified and demythologized, from linguistic and ideological meanings and understandings associated with the evolutionary mode of human production, by the techniques of phenomenology and the scientific process. Be that as it may, for phenomenological structuralism, in keeping with the empiricist logic of Bertrand Russell, "outside of human desires there are no moral standards." Morality or moral standards are associated with the linguistic and ideological desires (power and power positions) of those who control the resources and mode of production of a material resource framework via their language, ideology, ideological apparatuses, and communicative discourse (i.e., social class language game). It (moral practices and statements) constitutes a part of the superverse/multiverse as phenomenal properties of subatomic particles once disaggregated as lived-experience [38]. In that sense, assuming the phenomenal properties of subatomic particles get recycled between the superverse and its multiverses as I am positing here, morality is an epiphenomenon of lived-experience and becomes an emergent property of the superverse and its multiverses, which constitute the lwas (platonic forms or concepts such as beauty, justice, egalitarianism, etc.) of Haitian metaphysics that human reason, which are the recycled subatomic neuronal/chemical particles of the superverse and multiverse operating through DNA and its aggregation as the brain and mind (perception), can reflect upon to constitute their being-in-the-world (practical consciousness) in relation to the language, ideology, etc., i.e., social class language game, of those who precedes individual existence. Ostensibly, social change, following subatomic particle aggregation, is tied to both the 1) differentiating affects and techniques of the social class language game of those who control the material resource framework of (an) earth, 2) and the ability to defer meaning in ego-centered communicative discourse, via symbols, language, ideology, etc., which encapsulates or is the medium by which the lwas (concepts) of the superverse and its multiverses are expressed as human practical consciousness in material worlds.

\section{Acknowledgement}

None.

\section{Conflict of Interest}

No conflict of interest.

\section{References}

1. Mocombe Paul C (2019) The Theory of Phenomenological Structuralism. Cambridge Scholars Publishing, Newcastle, UK.

2. Hameroff Stuart, Roger Penrose (2014) Consciousness in the Universe: A Review of the 'Orch OR' theory. Phys Life Rev 11(1): 39-78.

3. Mocombe Paul C (2016) The Vodou Ethic and the Spirit of Communism: The Practical Consciousness of the African People of Haiti. University Press of America, Maryland, USA.

4. Crothers Charles (2003) Technical Advances in General Sociological Theory: The Potential Contribution of Post-Structurationist Sociology. Perspectives 26(3): 3-6.
5. Ortner Sherry (1984) Theory in Anthropology Since the Sixties. Comparative Studies in Society and History 26(1): 126-166.

6. Althusser Louis (2001) Lenin and Philosophy and Other Essays. Monthly Review Press, NYU Press, New York, USA.

7. Althusser Louis, Étienne Balibar (1970) Reading Capital. In: Ben Brewster (Ed.), NLB, London, UK.

8. Balibar Etienne, Immanuel Wallerstein (1991) Race, Nation, Class: Ambiguous Identities. Verso, London, UK.

9. Buck Morss Susan (2009) Hegel, Haiti, and Universal History. University of Pittsburgh Press, Pittsburgh, USA.

10. Cohen J (2002) Protestantism and Capitalism: The Mechanisms of Influence. Aldine de Gruyter, New York, USA.

11. Dahrendorf Ralf (1959) Class and Class Conflict in Industrial Society. Stanford University Press, California, USA.

12. Douglas M (1986) How Institutions Think. Syracuse University Press, New York, USA.

13. Du Bois Laurent (2004) Avengers of the New World. Harvard University Press, Cambridge, Massachusetts, UK

14. Fraser Nancy (1997) Justice Interruptus: Critical Reflections on the "Postsocialist" Condition. Routledge, London, UK.

15. Holloway Joseph E (1990a) Africanisms in American Culture. In: Holloway Joseph E (Ed.), Indiana University press, Bloomington Indiana, USA.

16. Holloway Joseph E (1990b) The Origins of African-American Culture. In Joseph Holloway (Ed.), Africanisms in American Culture, Indiana University Press, Bloomington and Indianapolis, USA, pp. 19-33.

17. Horkheimer Max, Theodor W Adorno (2000) Dialectic of Enlightenment. In: Theodor Adorno, John Cumming (Eds.), Kindle Edition, Continuum, New York, USA.

18. Hudson Kenneth, Andrea Coukos (2005) The Dark Side of the Protestant Ethic: A Comparative Analysis of Welfare Reform. Sociological Theory 23 (1): 1-24.

19. James CLR (1986) The Black Jacobins: Toussaint L Ouverture and the San Domingo Revolution. Vintage Books, New York, USA.

20. Karenga Maulana (1993) Introduction to Black Studies. The University of Sankore Press, California, USA.

21. Kellner Douglas (2002) Theorizing Globalization. Sociological Theory 20(3): 285-305.

22. Kurtz Lester R (2012) Gods in the Global Village: The World's Religions in Sociological Perspective. Sage Publications, California, USA.

23. Lukács Georg (1971) History and Class Consciousness: Studies in Marxist Dialectics. In: Rodney Livingstone (Ed.), The MIT Press, Massachusetts, Cambridge, UK.

24. Lukács, Georg (2000) A Defence of History and Class Consciousness: Tailism and the Dialectic. In: Esther Leslie (Ed.), Verso London, Uk.

25. Marcuse Herbert (1964) One-Dimensional Man. Beacon Press, Boston, Massachusetts, USA.

26. Marcuse Herbert (1974) Eros and Civilization: A Philosophical Inquiry into Freud. Beacon Press, Boston, Massachusetts, USA.

27. Marx Karl, Friedrich Engels (1964) The Communist Manifesto. Penguin Books, London, England, UK.

28. Marx Karl (1992) Capital: A Critique of Political Economy Volume I: The Process of Capitalist Production [1867]. In: Samuel Moore, Edward Aveling (Eds.), International Publishers, New York, USA.

29. Marx Karl (1998) The German Ideology. Prometheus Books, New York, USA.

30. McMichael Philip (2008) Development and Social Change: A Global Perspective. Sage Publications, Los Angeles, California, USA. 
31. Mocombe Paul C (2009) The Soul-less Souls of Black Folk: A Sociological Reconsideration of Black Consciousness as Du Boisian Double Consciousness. University Press of America, Maryland, USA.

32. Patterson Orlando (1982) Slavery and Social Death: A Comparative Study. Harvard University Press, Massachusetts, Cambridge, UK.

33. Ramsey Kate (2011) The Spirits and the Law: Vodou and Power in Haiti. University of Chicago Press, Chicago, USA.

34. Rubin Vera (1960) Caribbean Studies: A Symposium. University of Washington Press, Seattle, Washington, USA.

35. Sklair Leslie (1995) Sociology of the Global System. Westview Press, Baltimore, Maryland, USA.
36. Smith MG (1960) The African Heritage in the Caribbean. Caribbean Studies: A Symposium. In Vera Rubin (Ed.), University of Washington Press, Seattle, Washington, USA, pp. 34-46.

37. Wallerstein Immanuel (1982) The Rise and Future Demise of the World Capitalist System: Concepts for Comparative Analysis. Introduction to the Sociology of Developing Societies. In: Hamza Alavi, Teodor Shanin (Eds.), Monthly Review Press, New York, USA, pp. 29-53.

38. Weber Max (1958) The Protestant Ethic and the Spirit of Capitalism. In: Talcott Parsons (Ed.) Charles Scribner's Sons, New York, USA. 